\title{
Dos Direitos da Personalidade
}

ISABEL CECÍLIA DE OLIVEIRA BEZERRA

Especialista e Mestre em Direito pela UFC. Advogada da União. Professora de Direito Civil e de Direito Processual Civil na FA7. isabel.bezerra@oi.com.br

Sumário: 1) Introdução; 2) Evolução; 3) Terminologia; 4) Conceito; 5) Destinatários; 6) Previsão normativa; 7) Características; 8) Classificação; 9) Proteção jurídica; 10) Considerações finais; 11) Referências bibliográficas.

Resumo: O trabalho tem por finalidade o estudo dos direitos da personalidade, categoria de direitos assegurados aos seres humanos pelo simples reconhecimento de sua natureza humana, com a finalidade de resguardar a sua existência e dignidade, mediante a proteção dos seus atributos físicos, intelectuais e morais. Em seu bojo, realiza-se a análise de diversos aspectos gerais ao tema relacionados, como a evolução de sua teorização, a terminologia adotada para a categoria dos direitos em referência, seus diversos conceitos, destinatários ativos e passivos, previsão normativa no direito pátrio, principais características e classificações, e os diversos mecanismos disponibilizados pelo ordenamento para sua proteção jurídica.

Palavras-chave: Constitucional. Direitos. Personalidade.

\section{INTRODUÇÃO}

Considerando que a teorização dos direitos da personalidade é bastante recente, datando do final do século passado, muitas divergências existem a respeito desta nova categoria de direitos, fenômeno que se verifica não somente em nosso país, mas em diversos outros ordenamentos jurídicos.

Deste modo, a imaturidade do instituto desperta a necessidade de que a matéria seja estudada e desenvolvida, pressuposto inafastável para o seu pleno reconhecimento e aplicação pelos diversos segmentos da sociedade brasileira. 
O presente trabalho, portanto, tem por finalidade contribuir para que os direitos da personalidade sejam definitivamente implementados em nosso ordenamento jurídico, mediante a explicitação de diversas informações relacionadas aos seus aspectos gerais.

\section{$\infty$ EvoluÇão}

Em diversas épocas históricas, normas jurídicas isoladas conferiram proteção a aspectos singulares da personalidade humana, sem a preocupação, contudo, de que o próprio ser humano era merecedor de respeito e consideração.

Somente com o Cristianismo, o Direito Natural e o Iluminismo, foram implementadas concepções iniciais de que ao homem deveriam ser assegurados direitos essenciais de existência e dignidade.

O positivismo, entretanto, impediu o florescimento da teorização dos direitos da personalidade. Durante muitos anos, o reconhecimento da existência dos direitos da personalidade foi negado pelas concepções doutrinárias positivistas sob o argumento de que não se fazia possível a existência de direitos da pessoa sobre a própria pessoa, sendo inadequado o entendimento de que o ser humano pudesse ser objeto de direito.

A catástrofe implementada pela Segunda Guerra Mundial exigiu dos juristas a reformulação dos seus conceitos. Principalmente na Alemanha, após o citado evento, viu-se a necessidade de que fossem resguardados, com maior intensidade, os direitos essenciais da pessoa humana.

Após o termo da Segunda Guerra Mundial, desastroso evento que resultou na dizimação física e psíquica de milhares de seres humanos, os juristas alemães foram conduzidos ao aprimoramento dos direitos que se faziam necessários para o asseguramento da existência e da dignidade humana, culminando com a teorização dos direitos da personalidade.

Consoante doutrina Henrich Lehmann ${ }^{1}$, jurista alemão:

La época posterior a la guerra mundial trajo para Alemania uma posición fundamentalmente nueva frente a la valoración de los bienes de la vida. Se rompió com la varorazión jurídica romana, según la que el Derecho Privado es, em primer término, decrecho patrimonial, y la propriedad constituye el eje del sistema jurídico. Frente a ello se situo em primer término al hombre, a la personalidad humana, como miembro más valioso y creador de valores de todo el organismo social, pronunciándose así la supremacia del hombre vivo frente a las cosas muertas.

${ }^{1}$ LEHMANN, Heinrich. Tratado de Derecho Civil. Parte General. Vol. 1. Madrid: Editorial Revista de Derecho Privado, 1956. Pág. 577. 
Após a superação da Segunda Grande Guerra, portanto, iniciou-se o desenvolvimento doutrinário ou a teorização dos direitos da personalidade, a partir da análise de decisões jurisdicionais prolatadas na Alemanha, em casos concretos apreciados por julgadores que reconheciam a existência de uma nova categoria de direitos merecedores de especial proteção.

Larenz $^{2}$, a propósito, também jurista alemão, destaca que:

Na Alemanha, a sensibilidade, depois da guerra, em face de toda sorte de menosprezo à dignidade humana e desapreço à personalidade por parte do Estado e a multiplicação dos atentados a esta por particulares em razão dos progressos da técnica moderna, incentivaram os tribunais a reconhecer, com fundamento em artigos da Constituição, o denominado direito geral da personalidade, isto é, o direito da pessoa humana a ser respeitada e protegida em todas as suas manifestações imediatas dignas de tutela jurídica, assim como na sua esfera privada e íntima (grifo nosso).

Com efeito, consoante noticia Erasmo M. Ramos, doutorando em Direito pela Universidade de Frankfurt - Alemanha, foi uma decisão jurisdicional do Tribunal Superior Alemão de 1954 (BGHZ 13, 334) a primeira a reconhecer a existência de direitos intrínsecos à personalidade humana, ao assegurar a um determinado indivíduo o direito ao respeito e ao desenvolvimento de sua personalidade, a partir da aplicação do § 823 do BGB $^{3}$. Desde então, não parou de crescer o desenvolvimento da matéria, tanto na Alemanha como em outros países do mundo.

\section{$\checkmark$ Terminologia}

A teorização dos direitos da personalidade, como vimos, foi desenvolvida inicialmente pelos juristas alemães, sendo estes os principais responsáveis pela definição dos seus elementos básicos, dentre os quais sua designação terminológica: individualrechte (direitos individuais), individualitätsrechte (direitos da individualidade), personalitätsrechte (direitos da personalidade) ou ainda persönlichkeitesrechte (direitos da individualidade e direitos sobre a própria pessoa). ${ }^{4}$

A divergência terminológica da doutrina alemã repercutiu na doutrina brasileira, sendo a matéria inicialmente denominada direitos subjetivos, direitos

2 GOMES, Orlando. Novos Temas de Direito Civil. Rio de Janeiro: Forense, 1983. Págs. 251/252.

3 RAMOS, Erasmo. Estudo Comparado do direito de personalidade no Brasil e na Alemanha. Revista dos Tribunais, São Paulo, ano 91, volume 799, p. 11-32, maio 2002. Pág. 26.

${ }^{4}$ FRANÇA, Limongi. Instituições de Direito Civil. 5. ed. São Paulo: Saraiva, 1999. Pág. 935. 
essenciais, direitos fundamentais, direitos pessoais, direitos individuais, direitos personalíssimos, e direitos privados da personalidade ${ }^{5}$, até finalmente firmar-se como direitos da personalidade, sendo esta, atualmente, a terminologia comumente utilizada pela doutrina, jurisprudência e legislação nacionais.

Com efeito, os direitos da personalidade são direitos subjetivos (direitos assegurados pelo direito objetivo aos sujeitos de direito), essenciais, pessoais (direitos cujo exercício se assegura à pessoa do seu titular) e individuais, mas nem todos os direitos subjetivos, essenciais, pessoais e individuais são direitos da personalidade; alguns direitos de personalidade são direitos fundamentais, mas nem todos os direitos fundamentais são direitos de personalidade; os direitos de personalidade são direitos personalíssimos (direito exclusivo ou privativo do respectivo titular), mas nem todos os direitos personalíssimos são direitos da personalidade; e, finalmente, os direitos privados da personalidade são apenas uma espécie do gênero direitos da personalidade, posto que se reconhece a existência de direitos públicos da personalidade, aqueles decorrentes de normas jurídicas de direito público.

Devemos esclarecer, ademais, consoante alerta Erasmo M. Ramos ${ }^{6}$, que a denominação direitos de personalidade deve sobrepor-se a direitos da personalidade, posto que os direitos de que tratamos não são titularizados pela personalidade, mas pelos sujeitos que a possuem.

\section{$\checkmark$ Conceito}

A personalidade não se confunde com os direitos da personalidade. Por personalidade se entende a qualidade do sujeito que lhe permite adquirir direitos e obrigações, a qualidade que confere aptidão ao seu respectivo titular, para ser sujeito ativo ou passivo de direitos. Por direitos da personalidade, a seu turno, devemos conceber a categoria de direitos reconhecidos aos seres humanos e necessários à sua existência e dignidade.

Se entendermos que os direitos da personalidade são uma categoria de direitos, adotamos, portanto, a concepção pluralista. Orlando Gomes ${ }^{7}$, a propósito, doutrina que os direitos da personalidade podem ser concebidos, segundo uma concepção unitarista, ou segundo uma concepção pluralista. A primeira, adotada no Direito Suíço, reconhece os direitos da personalidade como aqueles decorrentes do direito geral da personalidade, os quais não recebem conteúdo específico, sendo

\footnotetext{
${ }^{5}$ BITTAR, Carlos Alberto. O Direito Civil na Constituição de 1988. 2. ed. São Paulo: Revista dos Tribunais, 1991. Pág. 45.

${ }^{6}$ Idem 3. Pág. 12.

7 Idem 2. Págs. 252/254.
} 
identificados, delimitados e protegidos, nos casos concretos, pela jurisprudência. A segunda entende que por direitos da personalidade deve-se entender a categoria dos diversos direitos específicos da personalidade reconhecidos juridicamente e reunidos por características comuns, sendo adotada pela maioria dos ordenamentos jurídicos, dentre os quais o brasileiro.

O estudo da matéria, ademais, nos levou à observação de que os direitos da personalidade não podem ser conceituados de modo amplo, ou seja, como a categoria dos direitos assegurados pelo ordenamento jurídico às pessoas físicas ou jurídicas, pelo simples fato de serem detentoras de personalidade jurídica, posto que os direitos da personalidade foram teorizados para a garantia de direitos essenciais aos seres humanos, sendo estes os seus únicos destinatários.

$\mathrm{E}$ o que podemos entender por direitos da personalidade?

Jorge Miranda ${ }^{8}$ enumera alguns conceitos clássicos formulados sobre os direitos da personalidade, dentre os quais o elaborado por Cabral de Moncada, para quem direitos da personalidade "são posições jurídicas fundamentais do homem que ele tem pelo simples fato de nascer e viver"; por Gomes da Silva, como "aspectos imediatos da exigência de integração do homem"; por Orlando de Carvalho, no sentido de "condições essenciais ao seu ser e devir"; por Adriano de Cupis, para quem os direitos da personalidade "revelam o conteúdo necessário da personalidade", tendo por objeto "não algo de exterior do sujeito, mas modos de ser físicos e morais da pessoa"; por Adriano Vaz Serra, como "direitos de exigir de outrem o respeito da própria personalidade"; e por Carvalho Fernandes, como "bens da personalidade física, moral e jurídica."

Além disso, doutrina Erasmo M. Ramos ${ }^{9}$ que os direitos da personalidade são "os que afetam a própria personalidade de forma direta ou indireta e que devem ser exercitados pela própria pessoa violada”.

Segundo Silvio Rodrigues ${ }^{10}$, os direitos da personalidade são direitos subjetivos inerentes à pessoa humana, insusceptíveis de serem destacados do seu respectivo titular e a estes relacionados permanentemente.

R. Limongi França ${ }^{11}$, após esclarecer que os direitos de personalidade são aqueles cujas relações jurídicas incidem sobre a própria pessoa, conceitua-os como “as faculdades jurídicas cujo objeto são os diversos aspectos da própria pessoa do sujeito, bem assim da sua projeção essencial no mundo exterior.”

Para Carlos Alberto Bittar, os direitos da personalidade devem ser concebidos como os direitos incidentes sobre os modos de ser físicos, intelectuais e morais da

\footnotetext{
${ }^{8}$ MIRANDA, Jorge. Manual de Direito Constitucional. Tomo IV. 2. ed. Coimbra: Coimbra Editora, 1993. Págs. 55/56.

${ }^{9}$ Idem 3. Pág. 15.

${ }^{10}$ RODRIGUES, Silvio. Direito Civil - Parte Geral. Volume 1. 28. ed. São Paulo: Saraiva, 1998. Pág. 81.

${ }^{11}$ Idem 4. Pág. 935.
} 
pessoa, compreendendo-se prerrogativas ínsitas em sua personalidade e em suas projeções para a sociedade. São os direitos que se destinam à salvaguarda das prerrogativas próprias e ínsitas da natureza humana ${ }^{12}$.

Para arrematar, Maria Helena Diniz ${ }^{13}$ ensina que os direitos da personalidade são os direitos subjetivos de defesa dos bens jurídicos que são próprios aos seus titulares, como a integridade física, intelectual e moral.

Por fim, concebemos dos direitos da personalidade como a categoria de direitos assegurados aos seres humanos pelo simples reconhecimento de sua natureza humana, com a finalidade de resguardar a sua existência e dignidade, e mediante a proteção dos seus atributos físicos, intelectuais e morais.

\section{DestinatáRios}

Consoante esclarecemos acima, os direitos da personalidade não são categoria de direitos assegurados às diversas pessoas físicas ou jurídicas, pelo simples fato de serem detentoras de personalidade jurídica, pois foram teorizados para a garantia de direitos essenciais aos seres humanos, sendo estes os seus únicos destinatários ativos.

Os seres humanos, portanto, são os titulares dos direitos de personalidade, sem distinção de qualquer natureza, ou em decorrência da sua origem, raça, sexo, cor, idade, ou religião. A Constituição Federal assegura, em seu artigo $5^{\circ}$, caput, a igualdade de todos os homens perante a lei, sem distinção de qualquer natureza, garantindo-se aos brasileiros e aos estrangeiros residentes no País a inviolabilidade do direito à vida, à liberdade, à igualdade, à segurança e à propriedade.

Ademais, considerando que os direitos da personalidade são direitos absolutos ou erga omnes, pode-se inferir que os destinatários passivos da relação jurídica envolvendo os direitos da personalidade são todos os membros da sociedade. Em outros termos, todas as pessoas físicas ou jurídicas, de direito privado ou de direito público, são juridicamente obrigadas ao respeito dos direitos da personalidade, sob pena de incursão nas sanções penais e civis previstas no ordenamento jurídico. Com efeito, consoante doutrina Mario Rotondi ${ }^{14}$ os direitos da personalidade são "derechos subjetivos eminentemente absolutos, que miram a tutelar la integridad física y moral del indivíduo, imponiendo a la universalidad de los asociados la obligación negativa de uma abstención que se traduce em el respeto de todas las legítimas manifestaciones de la personalidad ajuna.”

\footnotetext{
${ }^{12}$ Idem 5. Pág. 45.

${ }^{13}$ DINIZ, Maria Helena. Curso de Direito Civil Brasileiro. $1^{\circ}$ Volume. 16. ed. São Paulo: Saraiva, 2000. Pág. 102.

${ }^{14}$ ROTONDI, Mario. Instituciones de Derecho Privado. Barcelona: Editorial Labor, 1953. Pág. 195.
} 


\section{Previsão Normativa}

Os direitos da personalidade encontram previsão normativa em diversas leis constitucionais, civis e penais, fenômeno verificado tanto no Brasil como em diversos outros países.

No ordenamento jurídico brasileiro, os direitos da personalidade encontramse dispostos principalmente na Constituição Federal de 1988, no Código Civil Brasileiro e no Código Penal Brasileiro, existindo ainda outras normas jurídicas que regulam a matéria.

Devemos ressaltar, contudo, que muito embora a maioria dos direitos da personalidade encontre previsão expressa em dispositivos normativos do ordenamento jurídico pátrio, existem direitos de personalidade não estabelecidos legalmente, mas reconhecidos unicamente pelo costume e/ou pela doutrina ${ }^{15}$.

A Constituição Federal dispõe sobre os direitos de personalidade principalmente no seu artigo $5^{\circ}$, caput e incisos I, III, V, VI, VIII, IX, X, XII, XXVII, XXVIII, XXIX, XXXV, XLI, XLII, XLIII, XLIX, LX, e LXXVI. ${ }^{16}$ Também podemos considerar normas jurídicas nacionais constitucionais, nos moldes do artigo $5^{\circ}, \S$ $2^{\circ}$, os dispositivos do Pacto São José da Costa Rica, nos termos do Decreto ${ }^{\circ}$ 4.463, de 8 de novembro de 2002.

${ }^{15}$ Idem 4. Pág. 937.

${ }^{16}$ Dispõe a Constituição Federal: "Art. $5^{\circ}$. Todos são iguais perante a lei, sem distinção de qualquer natureza, garantindo-se aos brasileiros e aos estrangeiros residentes no País a inviolabilidade do direito à vida, à liberdade, à igualdade, à segurança e à propriedade, nos termos seguintes: I - homens e mulheres são iguais em direitos e obrigações, nos termos desta Constituição; (...) III - ninguém será submetido a tortura nem a tratamento desumano ou degradante; (...) V - é assegurado o direito de resposta, proporcional ao agravo, além da indenização por dano material, moral ou à imagem; VI - é inviolável a liberdade de consciência e de crença, sendo assegurado o livre exercício dos cultos religiosos e garantida, na forma da lei, a proteção aos locais de culto e a suas liturgias; VIII - ninguém será privado de direitos por motivo de crença religiosa ou de convicção filosófica ou política, salvo se as invocar para eximir-se de obrigação legal a todos imposta e recusar-se a cumprir prestação alternativa, fixada em lei; IX - é livre a expressão da atividade intelectual, artística, científica e de comunicação, independentemente de censura ou licença; X - são invioláveis a intimidade, a vida privada, a honra e a imagem das pessoas, assegurado o direito à indenização pelo dano material ou moral decorrente de sua violação; XII - é inviolável o sigilo da correspondência e das comunicações telegráficas, de dados e das comunicações telefônicas, salvo, no último caso, por ordem judicial, nas hipóteses e na forma que a lei estabelecer para fins de investigação criminal ou instrução processual penal; (...) XXVII - aos autores pertence o direito exclusivo de utilização, publicação ou reprodução de suas obras, transmissível aos herdeiros pelo tempo que a lei fixar; XXVIII - são assegurados, nos termos da lei: a) a proteção às participações individuais em obras coletivas e à reprodução da imagem e voz humanas, inclusive nas atividades desportivas; b) o direito de fiscalização do aproveitamento econômico das obras que criarem ou de que participarem aos criadores, aos intérpretes e às respectivas representações sindicais e associativas; XXIX - a lei assegurará aos autores de inventos industriais privilégio temporário para sua utilização, bem como proteção às criações industriais, à propriedade das marcas, aos nomes de empresas e a outros signos distintivos, tendo em vista o interesse social e o desenvolvimento tecnológico e econômico do País; (...) XXXV - a lei não excluirá da apreciação do Poder Judiciário lesão ou ameaça a direito; (...) XLI - a lei punirá qualquer discriminação atentatória dos direitos e liberdades fundamentais; XLII - a prática do racismo constitui crime inafiançável e imprescritível, sujeito à pena de reclusão, nos termos da lei; XLIII - a lei considerará crimes inafiançáveis e insuscetíveis de graça ou anistia a prática da tortura, o tráfico ilícito de entorpecentes e drogas afins, o terrorismo e os definidos como crimes hediondos, por eles respondendo os mandantes, os executores e os que, podendo evitá-los, se omitirem; (...) XLIX - é assegurado aos presos o respeito à integridade física e moral; (...) LX - a lei só poderá restringir a publicidade dos atos processuais quando a defesa da intimidade ou o interesse social o exigirem; (...) LXXVI - são gratuitos para os reconhecidamente pobres, na forma da lei: a) o registro civil de nascimento; b) a certidão de óbito; (...) $\S 1^{\circ}$. As normas definidoras dos direitos e garantias fundamentais têm aplicação imediata. $\S 2^{\circ}$. Os direitos e garantias expressos nesta Constituição não excluem outros decorrentes do regime e dos princípios por ela adotados, ou dos tratados internacionais em que a República Federativa do Brasil seja parte." 
O Código Civil Brasileiro, instituído pela Lei n 10.406, de 10 de janeiro de 2002, reservou especial capítulo para a matéria, disciplinando-a nos seus artigos 11 a $21^{17}$.

O Decreto-Lei n 2.848, de 7 de dezembro de 1940, a seu turno, que instituiu o Código Penal Brasileiro, prevê a tipificação de diversos delitos e respectivas sanções penais para os responsáveis por violação dos direitos da personalidade.

Ademais, o Direito Brasileiro ainda dispõe de outras normas jurídicas que asseguram proteção especial aos direitos da personalidade, como por exemplo, a Lei ${ }^{\circ} 9.434$, de 4 de fevereiro de 1997, que dispõe sobre a remoção de órgãos, tecidos e partes do corpo humano para fins de transplante e tratamento; a Lei ${ }^{\circ}$ 8.069, de 13 de julho de 1990, que dispõe sobre o Estatuto da Criança e do Adolescente; a Lei ${ }^{\circ}$ 8.501, de 30 de novembro de 1992, que dispõe sobre a utilização de cadáver não reclamado, para fins de estudos ou pesquisas científicas; a Lei $n^{\circ}$ 5.250, de 9 de fevereiro de 1967, que regula a liberdade de manifestação do pensamento e de informação; as Leis $n^{\circ} 4.117$, de 27 de agosto de 1962 e ${ }^{\circ}$ 9.472, de 16 de julho de 1997, que estabelecem normas sobre radiodifusão; a Lei $\mathrm{n}^{\circ}$ 9.610, de 19 de fevereiro de 1998, que dispõe sobre direitos autorais; a Lei ${ }^{\circ}$ 9.279 , de 14 de maio de 1996, que regula direitos e obrigações relativos à propriedade industrial, a Lei $\mathrm{n}^{\circ} 6015$ de 31 de dezembro de 1973, que dispõe sobre os registros públicos, a Lei ${ }^{\circ} 10.054$, de 07 de dezembro de 2000, que dispõe sobre a identificação criminal, e muitas outras.

\footnotetext{
${ }^{17}$ Dispõe o Código Civil Brasileiro: "Art.11. Com exceção dos casos previstos em lei, os direitos da personalidade são intransmissíveis e irrenunciáveis, não podendo o seu exercício sofrer limitação voluntária. Art. 12. Pode-se exigir que cesse a ameaça, ou a lesão, a direito da personalidade, e reclamar perdas e danos, sem prejuízo de outras sanções previstas em lei. Parágrafo único. Em se tratando de morto, terá legitimação para requerer a medida prevista neste artigo o cônjuge sobrevivente, ou qualquer parente em linha reta, ou colateral até o quarto grau. Art. 13. Salvo por exigência médica, é defeso o ato de disposição do próprio corpo, quando importar diminuição permanente da integridade física, ou contrariar os bons costumes. Parágrafo único. O ato previsto neste artigo será admitido para fins de transplante, na forma estabelecida em lei especial. Art. 14. É válida, com objetivo científico, ou altruístico, a disposição gratuita do próprio corpo, no todo ou em parte, para depois da morte. Parágrafo único. O ato de disposição pode ser livremente revogado a qualquer tempo. Art. 15. Ninguém pode ser constrangido a submeter-se, com risco de vida, a tratamento médico ou a intervenção cirúrgica. Art. 16. Toda pessoa tem direito ao nome, nele compreendidos o prenome e o sobrenome. Art. 17. O nome da pessoa não pode ser empregado por outrem em publicações ou representações que a exponham ao desprezo público, ainda quando não haja intenção difamatória. Art. 18. Sem autorização, não se pode usar o nome alheio em propaganda comercial. Art. 19. O pseudônimo adotado para atividades lícitas goza da proteção que se dá ao nome. Art. 20. Salvo se autorizadas, ou se necessárias à administração da justiça ou à manutenção da ordem pública, a divulgação de escritos, a transmissão da palavra, ou a publicação, a exposição ou a utilização da imagem de uma pessoa poderão ser proibidas, a seu requerimento e sem prejuízo da indenização que couber, se lhe atingirem a honra, a boa fama ou a respeitabilidade, ou se destinarem a fins comerciais. Parágrafo único. Em se tratando de morto ou de ausente, são partes legítimas para requerer essa proteção o cônjuge, os ascendentes ou os descendentes. Art. 21. A vida privada da pessoa natural é inviolável, e o juiz, a requerimento do interessado, adotará as providências necessárias para impedir ou fazer cessar ato contrário a esta norma.".
} 


\section{Características}

Ao estudarmos a terminologia dos direitos da personalidade, vimos que os mesmos são direitos subjetivos (direitos assegurados pelo direito objetivo aos sujeitos de direito), essenciais (direitos indispensáveis aos seres humanos), pessoais ou individuais (direitos cujo exercício se assegura à pessoa do seu titular) e personalíssimos (direitos exclusivos ou privativos do respectivo titular). Estas características, contudo, não são conferidas unicamente aos direitos da personalidade, mas a diversos outros direitos.

Muitos outros atributos podem ser conferidos aos direitos da personalidade, sendo capazes, quando considerados conjuntamente, de os distinguir de outras categorias de direitos.

Para citar apenas algumas manifestações doutrinárias, podemos destacar que Maria Helena Diniz ${ }^{18}$ doutrina que "os direitos da personalidade são absolutos, intransmissíveis, indisponíveis, irrenunciáveis, ilimitados, imprescritíveis, impenhoráveis e inexpropriáveis"; para Silvio Rodrigues ${ }^{19}$ os direitos da personalidade são "inalienáveis, intransmissíveis, imprescritíveis $e$ irrenunciáveis"; para Carlos Alberto Bittar $^{20}$ os mesmos direitos são “intransmissíveis, indispensáveis, extrapatrimoniais, imprescritíveis, impenhoráveis, vitalícios, necessários e oponíveis erga omnes.”

Para o nosso entendimento, os direitos da personalidade são dotados das seguintes características:

São direitos subjetivos, posto que assegurados pelos ordenamentos jurídicos, de modo explícito ou implícito, aos seus sujeitos de direito;

São direitos essenciais, eis que são indispensáveis à própria existência e dignidade dos seres humanos;

São direitos pessoais ou individuais, pois o seu exercício se assegura à pessoa do seu respectivo titular;

São direitos personalíssimos, porque o seu exercício se assegura exclusivamente ou privativamente ao seu titular;

São direitos vitalícios, ou seja, são direitos que acompanham toda a vida dos seres humanos, desde o seu nascimento até a morte.

São direitos indisponíveis, posto que, na maioria dos casos, são direitos excluídos do âmbito de disposição onerosa ou gratuita dos respectivos titulares. Desta característica decorre sua inalienabilidade, ou seja, a impossibilidade de sua disposição onerosa. E neste sentido dispõe o artigo 13 do Código Civil Brasileiro

\footnotetext{
${ }^{18}$ Idem 13. Pág. 100.

${ }^{19}$ Idem 10. Pág. 81.

${ }^{20}$ Idem 5. Pág. 48.
} 
que "salvo por exigência médica, é defeso o ato de disposição do próprio corpo, quando importar diminuição permanente da integridade física, ou contrariar os bons costumes”. Mas se admite, nos moldes do artigo 13, parágrafo único, e 14, do Código Civil Brasileiro, a disposição do próprio corpo, desde que gratuita, para fins de transplante, ou depois da morte, com "objetivo científico, ou altruístico".

São direitos irrenunciáveis, eis que não podem ser objeto de renúncia, expressa ou tácita, consoante estabelece expressamente o artigo 11 do Código Civil Brasileiro. Não podem ser recusados, rejeitados, dispensados, renegados, abdicados ou abandonados por atos voluntários dos seus titulares.

São direitos intransmissíveis, pois não podem ter sua titularidade transferida de pessoa para pessoa, em decorrência de manifestação volitiva do seu titular, de outras pessoas físicas ou jurídicas, ou do próprio Estado. Encontra-se previsto no artigo 11 do Código Civil Brasileiro. Desta característica decorre sua impenhorabilidade, inexpropriação e imprescritibilidade.

São direitos absolutos ou erga omnes, ou seja, são direitos oponíveis contra todos os membros da sociedade, contra todas as pessoas físicas ou jurídicas, de direito privado ou de direito público.

São direitos não patrimoniais, ou seja, são direitos juridicamente reconhecidos independentemente de qualquer avaliação econômica ou mesmo da existência de qualquer expressão econômica.

\section{ClassificaÇão}

R. Limongi França ${ }^{21}$ foi um dos primeiros doutrinadores brasileiros a se preocupar com o estudo sistematizado dos direitos da personalidade, sendo de sua autoria a principal classificação dos direitos da personalidade.

Partindo da consideração de que os diversos direitos da personalidade correspondem a determinados aspectos da personalidade, classificou os direitos da personalidade em três grandes blocos, posteriormente exemplificados, de modo amplo, por Maria Helena Diniz ${ }^{22}$ :

Direitos à integridade física: 1.1. Direito à vida: os diversos direitos relacionados à concepção e à descendência (gene artificial, inseminação artificial, inseminação de proveta, etc); ao nascimento (aborto); ao leite materno; à procriação e ao planejamento familiar (limitação de filhos, esterilização masculina e feminina, pílulas e suas conseqüências); à proteção do menor (pela família e sociedade); à alimentação; à habitação; à educação; ao trabalho; ao transporte adequado; à segurança e integridade física; ao aspecto físico da estética humana; à proteção

\footnotetext{
${ }^{21}$ Idem 4. Págs. 939/941.

${ }^{22}$ Idem 13. Pág. 101.
} 
médica e hospitalar; ao meio ambiente ecológico; ao sossego e ao sono; ao lazer; à locomoção; ao desenvolvimento vocacional profissional e artístico; à liberdade; ao prolongamento artificial da vida; à reanimação; à velhice digna; à eutanásia e outros. 1.2. Direito ao próprio corpo vivo e/ou morto: os diversos direitos relacionados ao espermatozóide, óvulo, ao útero, ao cabelo; ao exame médico; à transfusão de sangue; à alienação do sangue; ao transplante; à experiência científica; à sexualidade, ao transexualismo, à alteração do próprio sexo; ao sepulcro, à cremação; ao culto religioso e outros.

Direitos à integridade intelectual: os diversos direitos relacionados à liberdade de pensamento, à autoria científica, artística e/ou literária, à invenção, ao esporte e ao espetáculo.

Direitos à integridade moral: os diversos direitos relacionados à liberdade civil, política e/ou religiosa; à honra; à honorificência; ao recato; ao segredo pessoal, doméstico, político, religioso e/ou profissional; à imagem; ao aspecto moral da estética humana; à identidade pessoal, familiar e/ou social; à identidade sexual.

No mesmo sentido, Carlos Alberto Bittar classifica os direitos da personalidade em direitos físicos (direito à vida, à integridade física, ao corpo, a partes do corpo, ao cadáver e às suas partes, à imagem, à voz), direitos psíquicos (direito à liberdade, à intimidade, à integridade psíquica, ao segredo), e direitos morais (direito à identidade, à honra, ao respeito, às criações intelectuais) ${ }^{23}$.

Outras classificações dos direitos da personalidade podem ainda ser explicitadas, como a formulada por J. J. Gomes Canotilho, que defende que os direitos de personalidade abarcam os direitos de estado (direito à cidadania), os direitos sobre a própria pessoa (direito à vida, à integridade moral e física, à privacidade), os direitos distintivos da personalidade (direito à identidade pessoal, à informática) e direitos de liberdade (direito à liberdade de expressão) ${ }^{24}$.

\section{円 ProteçÃo JuRÍdicA}

O ordenamento jurídico nacional atribui especial proteção constitucional, penal e civil, aos direitos da personalidade, impedindo a sua violação ou ameaça, quer pelos particulares, quer pelo próprio Estado.

Proteção constitucional: os principais direitos da personalidade constituem direitos fundamentais, previstos na Constituição Federal como normas jurídicas de hierarquia superior, sendo direcionadas à obediência dos particulares e do próprio Estado. Além disso, a mesma Constituição Federal prevê diversas garantias institucionais e processuais com o objetivo de defender os direitos da personalidade.

\footnotetext{
${ }^{23}$ Idem 5. Pág. 46/47.

${ }^{24}$ CANOTILHO, J. J. Gomes. Direito Constitucional e Teoria da Constituição, 6. ed. Coimbra: Almedina, 2002. Pág. 396.
} 
Proteção penal: a maioria dos direitos da personalidade são objeto de tutela específica do Direito Penal, que estabelece sanções penais contra os indivíduos que violam os referidos bens jurídicos, ora no próprio Código Penal, ora em diversas leis penais especiais.

Proteção civil: os direitos da personalidade, no âmbito civil, são tutelados por normas jurídicas que estabelecem meios processuais específicos em defesa dos direitos da personalidade in natura, visando a abstenção de quaisquer práticas danosas, bem como a possibilidade da reparação patrimonial por sua violação, mediante a indenização pelos danos materiais e morais sofridos. Neste sentido dispõe expressamente o artigo 12 do Código Civil Brasileiro, que "pode-se exigir que cesse a ameaça, ou a lesão, a direito da personalidade, e reclamar perdas e danos, sem prejuízo de outras sanções previstas em lei”.

\section{Considerações FinaIs}

A catástrofe implementada pela Segunda Guerra Mundial despertou a necessidade de que fossem resguardados, com maior intensidade, os direitos essenciais da pessoa humana. O lamentável evento conduziu inicialmente os juristas alemães ao aprimoramento dos direitos que se faziam necessários ao asseguramento da existência e da dignidade humana, culminando com a teorização dos direitos da personalidade, que se expandiu posteriormente pelo mundo inteiro.

A nova categoria de direitos submeteu-se a divergências terminológicas, as quais foram superadas pela adoção da denominação direitos da personalidade, comumente utilizada pela doutrina, jurisprudência e legislação atuais.

Seguindo a orientação doutrinária precedente, os direitos da personalidade, de um modo geral, devem ser concebidos como a categoria de direitos assegurados aos seres humanos pelo simples reconhecimento de sua natureza humana, com a finalidade de resguardar a sua existência e dignidade, e mediante a proteção dos seus atributos físicos, intelectuais e morais.

São direitos assegurados aos seres humanos, sem distinção de qualquer natureza, e exigem o respeito de todos os membros da sociedade.

Além disso, no ordenamento jurídico brasileiro, encontram-se previstos de modo implícito (costume e doutrina) ou explícito (Constituição Federal de 1988, Código Civil Brasileiro, Código Penal Brasileiro, e outras normas jurídicas), podendo ser caracterizados como direitos subjetivos, essenciais, pessoais ou individuais, personalíssimos, vitalícios, indisponíveis, inalienáveis, irrenunciáveis, intransmissíveis, impenhoráveis, inexpropriáveis, imprescritíveis, absolutos, e não patrimoniais.

Finalmente, devemos destacar que por sua indubitável relevância, encontram proteção jurídica em níveis constitucional, penal e civil. 


\section{C@ REFERÊNCIAS BibliogRÁfICAS}

BITTAR, Carlos Alberto. O Direito Civil na Constituição de 1988. 2. ed. São Paulo: Revista dos Tribunais, 1991.

CANOTILHO, J. J. Gomes. Direito Constitucional e Teoria da Constituição. 6. ed. Coimbra: Almedina, 2002.

DINIZ, Maria Helena. Curso de Direito Civil Brasileiro. $1^{\circ}$ v. 16. ed. São Paulo: Saraiva, 2000.

FRANÇA, Limongi. Instituições de Direito Civil. 5. ed. São Paulo: Saraiva, 1999. GOMES, Orlando. Novos Temas de Direito Civil. Rio de Janeiro: Forense, 1983.

LEHMANN, Heinrich. Tratado de Derecho Civil. Parte General. Vol. 1. Madrid: Editorial Revista de Derecho Privado, 1956.

MIRANDA, Jorge. Manual de Direito Constitucional. Tomo IV. 2. ed. Coimbra: Coimbra Editora, 1993.

RAMOS, Erasmo. Estudo Comparado do direito de personalidade no Brasil e na Alemanha. Revista dos Tribunais, São Paulo, ano 91, volume 799, p. 11-32, maio 2002.

RODRIGUES, Silvio. Direito Civil - Parte Geral. Volume 1. 28. ed. São Paulo: Saraiva, 1998.

ROTONDI, Mario. Instituciones de Derecho Privado. Barcelona: Editorial Labor, 1953.

\section{On The Rights Of Personality}

Abstract: This work aims to study the rights of personality, group of rights that protects all human beings only as a result of its nature. These rights aim to guarantee the existence and dignity of human beings by means of the protection of their physical, intellectual and moral values. It is analysed the various aspects related to the evolution of the theories, the concepts and terminology related to this theme, as well as normative prevision of these rights, their main characteristics and classification and different available mechanisms to protect them by the application of legal principles.

Keywords: Constitution. Rights. Personality 